\title{
Seismotectonic zoning of the Finnish-Bothnia region based on the structural analysis method
}

\author{
B. A. Assinovskaya ${ }^{1}$ and M. K. Ovsov ${ }^{1}$
}

Received 20 November 2014; accepted 25 November 2014; published 19 December 2014.

This study describes the experience of the application of computer technology "Structural analysis of geophysical data" and geodynamic study results for the purpose of seismic zoning of the region with a low seismic activity. In the Finnish-Bothnia region, including the sea water area, a number of potential seismogenic zones were identified. The results can be used to compile the map of possible earthquake sources in the future. KEYWORDS: Structural analysis; seismic zoning; low seismicity; earthquake; deep structure; active fault; GPS data;

strain field.

Citation: Assinovskaya, B. A. and M. K. Ovsov (2014), Seismotectonic zoning of the Finnish-Bothnia region based on the structural analysis method, Russ. J. Earth. Sci., 14, ES2005, doi:10.2205/2014ES000542.

\section{Introduction}

This paper is devoted to compilation of a map for seismotectonic zoning of the Finnish-Bothnia area and its margins (Figure 1). Despite the fact that the level of seismicity of the region is fairly low, it is yet worth looking into in terms of a few nuclear power stations located in the area, as well as other facilities of critical importance, such as the North Stream pipeline.

This regional seismic zonation mapping can be viewed as the first step in assessment of seismic hazard of any scale. Consequently, the map could provide a basis for further study of the possible earthquake sources with evaluation of maximum magnitude $M_{\max }$ and other parameters of seismicity.

It goes without saying that low seismicity areas present a complicated challenge to those trying to investigate them, which is due to the almost complete lack of direct data on active faults. It is known that they hardly ever manifest themselves on the surface if earthquake magnitudes are $\leq 5-6$. Besides, the information about the geology and geophysics of the water areas often is not available. In this case, it is common practice to call for an expert opinion; even if it is generally prone to subjectivity.

The paper proposes carrying out seismotectonic zoning of low activity areas, using the computer technology of structural analysis of geophysical data which was previously applied for this purpose only in our research [Assinovskaya and Ovsov, 2013. Indeed, the mentioned methodology has been freshly modified but it also comprises independent results of

\footnotetext{
${ }^{1}$ Geophysical Survey RAS, Saint Petersburg, Russia
}

geodynamic analysis of GPS data obtained by the authors for a more precise outline of active faults [Gorshkov et al., 2013 .

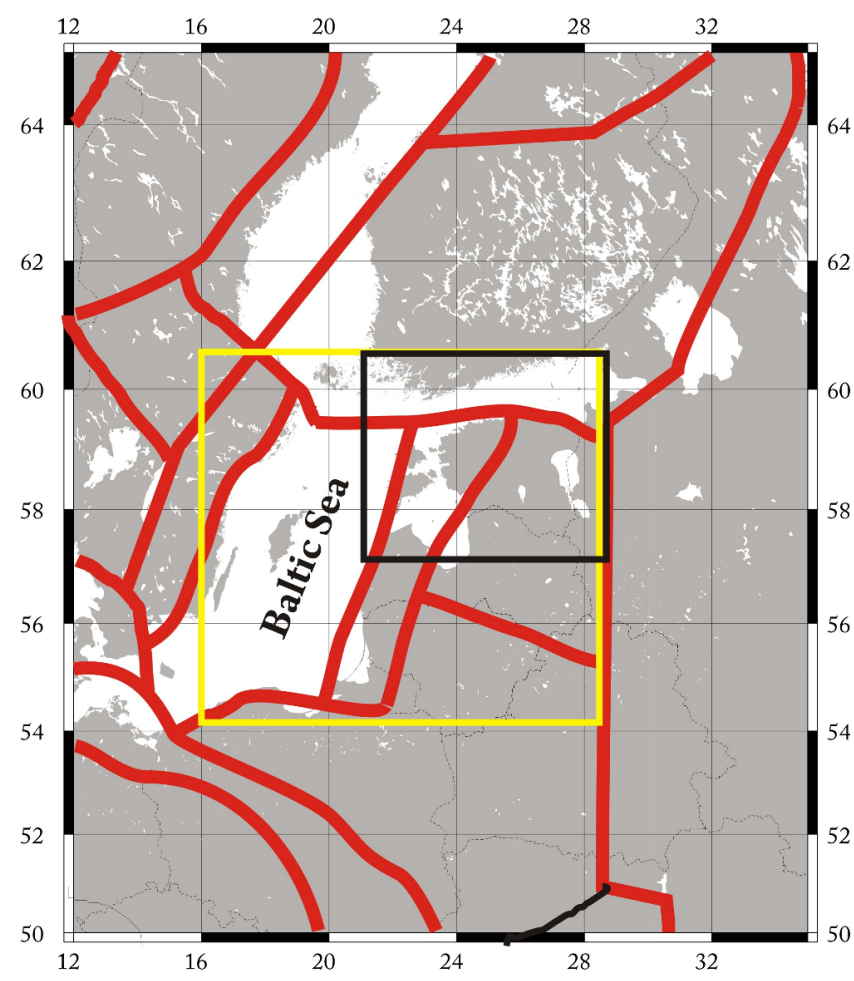

Figure 1. Fragment of the seismic zoning of the project SHARE (Seismic Hazard Harmonization in Europe, http://www.efehr.org:8080/jetspeed/portal/hazard.psml)). Yellow and black rectangles are the area of study from [Assinovskaya and Ovsov, 2013] and this paper respectively. 
It is true that both global and local seismic hazards assessment are evaluated on a regular basis, namely as part of the projects GHAP and SHARE that cover the territory of Europe, and OCP-2012-14 for Russia [Bommer, 2010. Jiménez et al., 2001. Ulomov and Bogdanov, 2013. Based on the SHARE project, GHAP maps of Europe have been updated including its northern territories as well. However, the Baltic Sea area and other numerous water spaces have still remained a blind spot.

According to the seismic hazard map of the SHARE project Figure 1, the region under study is located within several domains (Figure 1). Our previous paper demonstrated that the Eastern Baltic region proved to have a far more complex configuration of domains (Figure 1) and active lineaments are revealed within their borders [Assinovskaya and Ovsov, 2013.

\section{Brief Description of Geological Structure}

The area under the study comprises the southern periphery of the Svecofennian domain of Fennoscandian Shield in the north and the northern part of the more young Baltic Syneclise in the south [Gorbachev and Bogdanova, 1993]. Some authors give particular regions a more detailed account of their geological structure [Kirs et al., 2009. Koistinen et al., 2001 Korsman et al., 1997. Vaisanen and Skytta, 2007.

The shield is composed of various metamorphosed sedimentary-volcanic and magmatic depositions (1.65$1.89 \mathrm{Ga}$ ). To illustrate, the South Finnish coast, as well as the bottom of the Gulf of Finland and Bothnian Bay, prove to be made up of aggregated blocks formed by supracrustal rocks, namely mica schists and gneiss, and also igneous rock of predominantly acidic composition, (The Late Svecofennian postorogenic granitoids). The blocks are marked by shear zones that coincide in extension with linear strains in the submarine and littoral relief. Thereby, according to [Vaisanen and Skytta, 2007], the area is characterized by a few fault zones cutting through the South Svecofennian igneous complex, particularly those of the arc-shaped South Finnish shear zone stretching along the north coast of the Gulf of Finland, and, orthogonal to the former, linear nonextended shear deformation zones (Figure 2). Some reports have identified Skonsero fault with $\mathrm{N}-\mathrm{W}$ trending [Koistinen et al., 2001 Korsman et al., 1997, orthogonally extended fracture in the N-E direction, and the Koporye fault off the southern coast of the Gulf of Finland [Korsman et al., 1997. The faults of the three directions $\mathrm{E}-\mathrm{W}, \mathrm{N}-\mathrm{W}$, and $\mathrm{S}-\mathrm{W}$ trending, which are likely to be neotectonically active have been identified as a result of field works on the island of Gogland [Assinovskaya and Verzilin, 2007.

The extensive and numerous intrusive rapakivi granites in compounds with felsic volcanic rocks deposited at $1.7 \mathrm{Ga}$ and later are equally widespread in the area (such as Vyborg rapakivi, Riga plutonic clasts, intrusions of the western Estonian coast and the south of the Bothnian Bay) [Korsman et al., 1997. Their fracturing properties may account for the specific effect they have on the recent tectonic pattern of the region. The crustal structure in zones of their occur- rence indicates distinct movements causing the formation of small blocks that create an effect of a "broken dish" [Berzin et al., 1979.

The basement of the southern part of the region manifests the North Estonian Paleoproterozoic folded zone [Kirs et al., 2009, composed of some crustal blocks (Figure 2). The North Estonian zone is divided by the relatively wide ( $30 \mathrm{~km}$ ) Paldiski-Pskov deformation zone with $\mathrm{N}-\mathrm{W}$ trending from the Estonian-Latvian Granulite Belt [Kirs et al., 2009 , which is made up of basic metamorphic rocks with intense shear patterns. The latter structure is dominated by metabasites and granites of enderbite-charnokite range. According to [Kirs et al., 2009, the northern branch of the Paldiski-Pskov zone extends in the $\mathrm{N}-\mathrm{W}$ direction, whereas the southern one is jointed with the E-W Middle Estonian fault zone. The North Estonian zone is structurally and lithologically non-homogeneous, being formed by granitegneiss-migmatite massives and folded zones with multiple granitoid intrusions [Kirs et al., 2009]. The N-E KurzemeParnu fault zone (Tapa) separates the metasedimentary depositions of Alitugase to the east of the metavolcanics and granitoids of the Tallinn zone.

It is well known that the Baltic Syneclise is an asymmetric depression filled with terrigenous-carbonate sediments in the age range of the Vendian to Quaternary periods and thickness increasing up to $4 \mathrm{~km}$ in the $\mathrm{S}-\mathrm{W}$ direction.

The deep structure of the region has been described in a number of works [Ankudinov et al., 1994] Ostrovsky, 1995 Yliniemi et al., 2001. Over the last few decades, the seismology of the Baltic region has been investigated in the framework of different international projects, for instance, SVEKOLAPKO et al. [Kozlovskaya et al., 2008. The collected data have served as a basis for compilation of maps of seismic waves velocity distribution, Moho depth, and upper and lower crust thickness of a various degree of detail [Grad et al., 2009] Janik, 2010] Tesauro et al., 2010]. According to these data, crust thickness varies in the range of $38-40 \mathrm{~km}$ in the eastern part of the Gulf of Finland and the zone around the junction of the Gulf of Finland and the Bothnian Bay, reaching a level of $62 \mathrm{~km}$ in the south of Finland, and up to $47-50 \mathrm{~km}$ around the Kurzeme peninsula. Therefore the gradient zones stretch along the nothern coast of the Gulf of Finland, exist at the Tallinn zone, they border the latitudinal Sweden-Saaremaa-Kurzeme-Gotland area. The thickness of upper crust is $30-42 \mathrm{~km}$, reaching its peak values around the island of Saaremaa, Tallin zone, and around Vyborg. The thickness of lower crust is $4 \mathrm{~km}$ at the junction of the Bothnia Bay and the Gulf Finland, sharply increasing to $12 \mathrm{~km}$ in the eastern part of the latter in the west of Estonia. The thickness of sedimentary cover rises from the uppermost dozens or hundreds of meters to $1 \mathrm{~km}$ in the direction of the Kurzeme peninsula. The basement is dislocated in many places by up to dozens of meters with displacement.

Neotectonic data on the region have been collected in form of small-scale schemes, such as the "Scheme of Latest Tectonic Elements of Central Europe" made by Garetsky et al., V. K. Gudelis [Garetzki and Nesmjanov, 2009], and Finnish and Swedish maps. The maps show structures and faults of various ranges. In this regard, the Helsinki-Petrozavodsk 


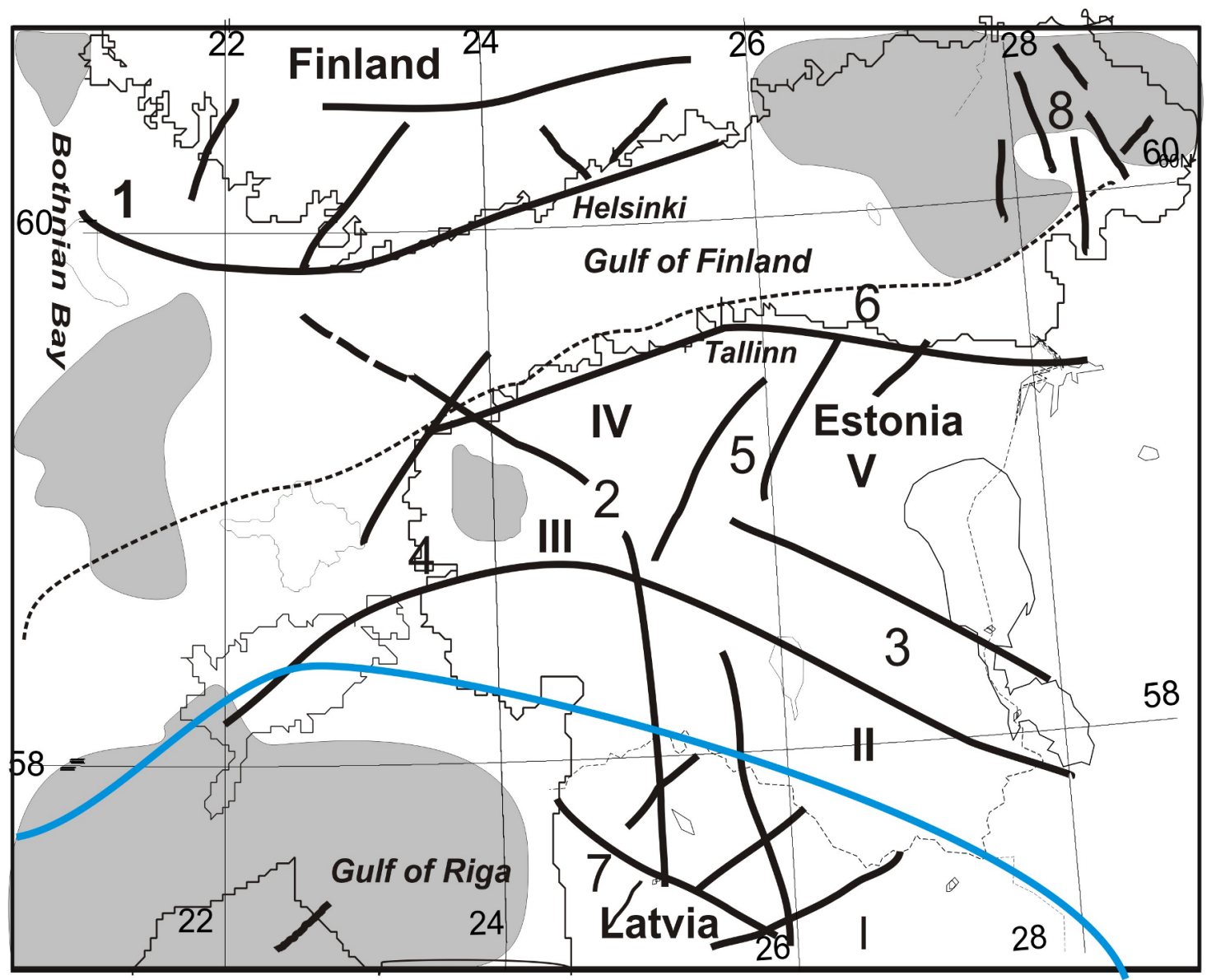

Figure 2. Elements of basement tectonics by [Kirs et al., 2009, Koistinen et al., 2001 Korsman et al., 1997. Sharov et al., 2007. Vaisanen and Skytta, 2007. Basement units: I, Estonian-Latvian granulite belt; II, South Estonian Zone; III, West-Estonian zone; IV, Tallinn zone; V, Alutaguse zone. Major faults: 1, Southern Finland shear zone; 2, Skonsero fault; 3, Paldisky-Pskov deformation zone; 4, Middle Estonian fault zone; 5, Tapa fault zone; 6, Koporsky fault; 7, North Latvian fault zone; 8, deformations within the Vyborg rapakivi intrusions. The position of the rapakivi intrusions and rapakivi-like granites is shown in gray. Thin black dashed line denotes the boundary of the Shield. Blue line shows the northern boundary of the Baltic syncline.

and Stockholm levels stand out from the rest. The Finnish graben zone extends from St. Petersburg to Pandivere High around Tallinn, at the same time, the Gotland-Bothnia zone relates to the Bothnian Bay and lies within the borders of the Aland elevation. "The Scheme of Latest Structures of the West Part of the Russian Platform and Adjacent Territories" [Garetzki and Nesmjanov, 2009] characterizes vertical neotectonic movements of the region. Thereby, the biggest downward movement has been registered to be by $200 \mathrm{~m}$, whereas the most tangible elevation has been by $100 \mathrm{~m}$.

As for the middle late Holocene movements, the data comprise only the east coast of the Baltic Sea [Garetzki and Nesmjanov, 2009, and manifest a dramatic contrast in movements of the Estonia-Kurzeme and Riga-Chudskoye blocks.

The heat flow in the south of the region is ubiquitously low [Gorgienko et al., 1987] Joeleht, Kukkonen, 1996, Majorowicz, Wybraniec, 2010, yet, it is higher within the north of the shield. In some spots along the coast of the Gulf of
Finland in Estonia, including areas nearby the source zone of the Osmussaar earthquake, at the depth of the first dozens of meters, there are local anomalies of increased heat flow density rising to $50-60 \mathrm{~mW} / \mathrm{m}^{2}$. High-intensity heat flow anomalies, such as the Klaipeda one, have not been registered in the area.

\section{Seismicity}

As result of the active systems of monitoring that have been applied in Finland, Estonia and north-west Russia since the 1960s, seismicity of the study area has been thoroughly investigated. Historical events have also been researched; they are presented in the database of the Seismology Institute in Helsinki, and in some publications as well www.seismo.helsinki.fi; Aronov, Aronova, 2009. Those 
mentioned data sources contain information of about 140 earthquakes that occurred in the time span between 1670 and 2012 and magnitude range of 1-4.7.

In course of the study, the earthquakes catalogue has been unified in terms of magnitude $M w$, which enabled evaluation of representativity of its historical and instrumental parts. It turned out that events with magnitude of $M w=2.6$ are representative in the first data selection (1750-1955), whereas the instrumental stage of research revealed all earthquakes with minimum magnitudes of $M w=1.6$. The sources of all seismic events are crustal and lie predominantly in the upper layer of the crust up to $17 \mathrm{~km}$ deep. A significant proportion of the earthquakes occurred in the uppermost layers at a depth not exceeding $1 \mathrm{~km}$. The most large event is considered to be the Estonian (Osmussaar) earthquake of 1976 with $M=4.7, H=17 \mathrm{~km}$, which caused a series of aftershocks [Ananjin et al., 1980]. The earthquake has been fairly well studied seismotectonically [Assinovskaya et al., 2013 Nikonov, 2002 Slunga, 1979. As a result, the earthquake focal mechanism has been defined as strike-slipreverse strike-slip in fault planes oriented in the direction of $162^{\circ}$ or $65^{\circ}$

A distinct regional property of distribution of sources is their clustering; there is evidence of sequences of weak events in 1894, 1952, and 1989. Some sequences have undergone a detailed study, for example, the Anjalankoski sequence of 2003 [Uski et al., 2006]. In 2011-2012, the same kind of sequence containing 86 events occurred on the north coast of the Gulf of Finland nearby Kuopola settlement, with the highest magnitude $M_{L}=2.6-2.7$, and focal depth of less than $1 \mathrm{~km}$. However, the sequence does not fall within the borders of the region under study. The Russian part of the region is marked by such historical events as the Narva earthquake of 1881 with magnitude $M=3.5$, and weaker but still felt events of 2007 in the Gulf of Finland and 2010 in Valaam (beyond the region). Seismic events as usual are caused tectonically, we are trying to explore these patterns in this paper.

\section{Data}

Since the character of seismic processes is determined by potential, geodynamic, and energetic properties of the crust and its structure the scope of the research into seismotectonic regionalization was set to draw on the following data: 1 . The magnetic anomaly maps $(T a)$ and the Bouguer anomaly gravity field maps $(G)$ of the Fennoscandian Shield, both in scale 1:2,000,000, produced by the Geological Survey of Finland [Korhonen et al., 2002a 2002b; corresponding maps of the Kalinigrad region, scale 1:1,000,000 [Shilova, Verbitsky, 2009 ; 2. Digital datasets on bathymetry and topography $(H)$ http://www.io-warnemuende.de/topography-ofthe-baltic-sea.html]. 3. Heat flow density data [Balling, 1995 Gorgienko et al., 1987 Majorowicz, Wybraniec, 2010 $(Q) ; 4$. GPS data on horizontal and vertical movements $(P L$, $Z)$ taken from a number of studies [Assinovskaya et al.,2011.
Lidberg et al., 2010. Most of the data has been converted into digital form.

The area of the region under study lies roughly within $20^{\circ} 20^{\prime} \mathrm{E}$ to $29^{\circ} 30^{\prime} \mathrm{E}$ and $57^{\circ} \mathrm{N}$ to $60^{\circ} 40^{\prime} \mathrm{N}$, and amounts to $165791 \mathrm{sq} \mathrm{km}$. The number of sites analyzed has corresponded to 166,865 for gravity field, 165,834 for magnetic field and 176,056 for relief, 176,056 for heat flow, and 175,372 for geodynamics accordingly. The data are given in proportion to the overall network density of $1 \times 1 \mathrm{~km}$.

In the final stage, in order to determine active faults, the study used the results of GPS data analysis in form of maps of deformation [Gorshkov et al., 2013]. Even though the analysis did not include the data on earthquakes, the latter was put in the basis of quality criteria in compilation of the map.

\section{Applied Method}

The map of seismic regionalization was developed using the "Structural Analysis" computer technology [Ovsov, 2000a 2000b 2001. This technology comprises a number of multivariable methods, including factorial, cluster, dispersion analyses, and others. The technology takes shape in three general-purpose computer programs, therefore it has been described in quite a detail. It is worth noting that factorial analysis has already been applied earlier in seismological research [Grachev and Nikolaev, 2002].

The "Structural Analysis" technology is based on the idea that crustal structure is represented in form of a hierarchical system of structural levels, or that is, a hierarchical system-related structural model. The model constitutes a tree-type structure expanding either from top to bottom, or from higher-level elements (general, comprehensive ones) down to lower-level elements (local and detailed ones).

In the first stage of analysis, the data is divided into components with an aim to define those ones whose variability is substantially related to the properties of geologic structures of interest, like those of intensity of properties, their size, form, and depth. Local anomalies are set to be determined by averaging of data around the observation site. They are then calculated as a differential between the initial value (observed one) and the average of the parameter. In this respect, division of data is crucial for glitch filtering and exclusion of regional background. Figure 3 shows an example of results of the primary data analysis.

The structural analysis itself is applied on the second stage, it constitutes a technique of "pattern recognition without learning" based on logical theory of classification [Ovsov, 1997. 2000a, 2000b, 2001, 2005. Rozova, 1986. Over the course of the last few decades, similar data processing systems have been extensively developed to be based on new multivariable analysis methods [Alexandrov, 2000].

The multilevel hierarchical structure of data is built concurrently. The first step is to divide the initial number of observation sites into a small number of classes that comprise the main and largest areas. By saying "class", we mean a relatively homogeneous subset of data in terms of intensity of features. All further steps use the same algorithm of division 

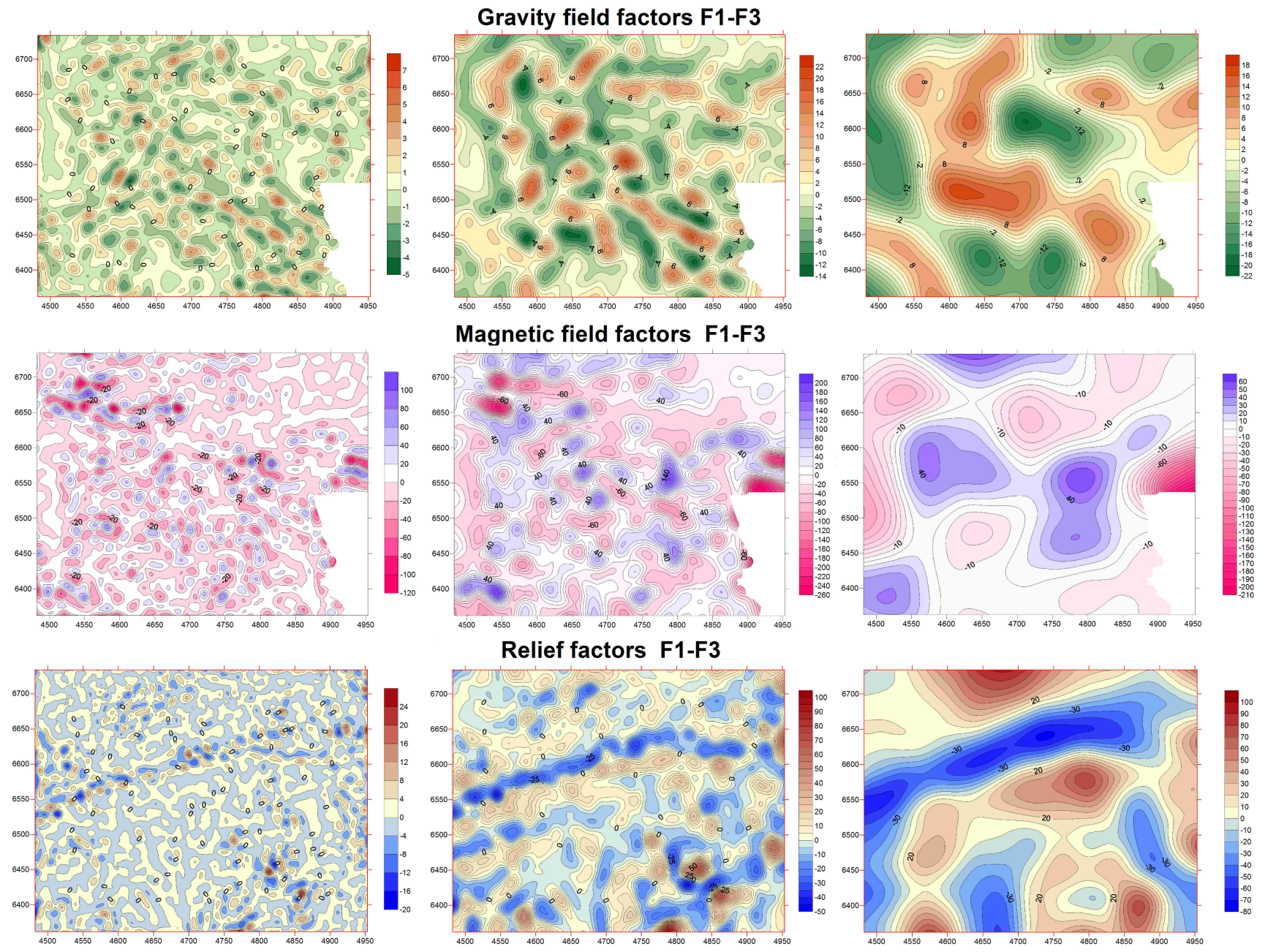

GPS horizontal and vertical velocity movements factors
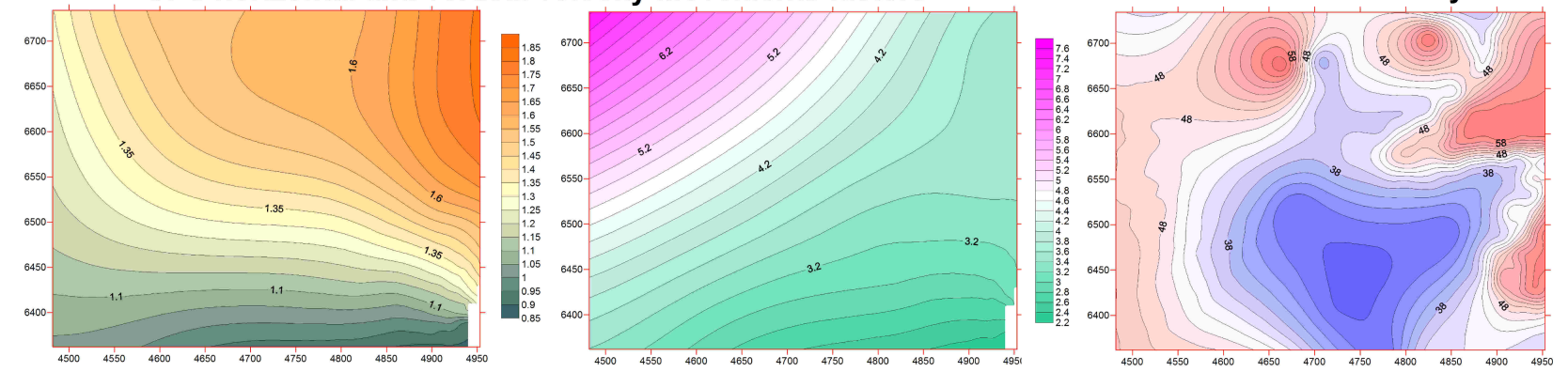

Figure 3. First stage of research. The local, intermediate and regional components (left to right) of the Bouguer anomaly gravity maps, magnetic anomaly maps (both in conventional units) and topography $(\mathrm{m})$ are shown on the top three rows respectively. Geodynamical (mm/year) and geothermal $\left(\mathrm{mW} / \mathrm{m}^{2}\right)$ data (bottom rows) are not separated on the components because of a small amount of data.

in relation to specified classes, etc. As a result, the initial class takes shape of a hierarchical tree-type structure. There are two main stages of data transformation taking place during conversion of the initial data into datasets: analysis of variables and analysis of objects, that is, observation sites. Bearing those stages in mind, one can characterize the structural division as determination of main classes in the feature space of the key factors.
The main generalized features of the set of initial features are determined as main oblique angle factors [Ovsov, 1990]. Calculations are made in the following order:

1. transformation of initial features into orthogonal components without changing the dimensions of feature space;

2. cluster analysis of initial features in orthogonal space 

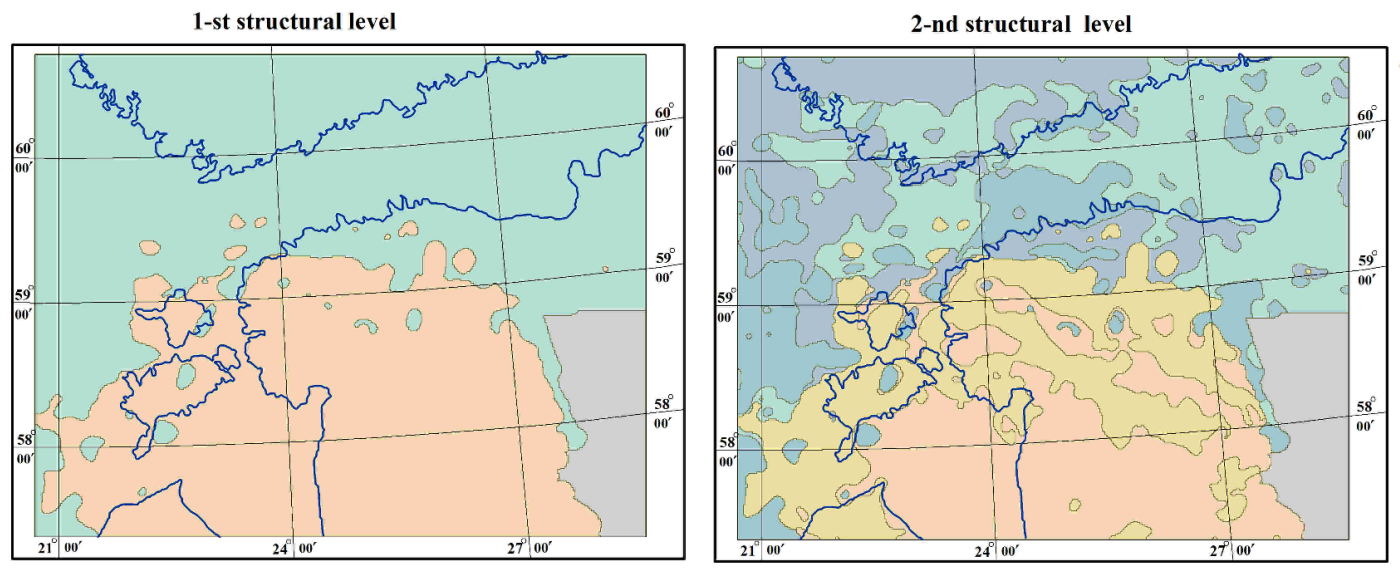

classification data structure

3-d structural level

4-th structural level
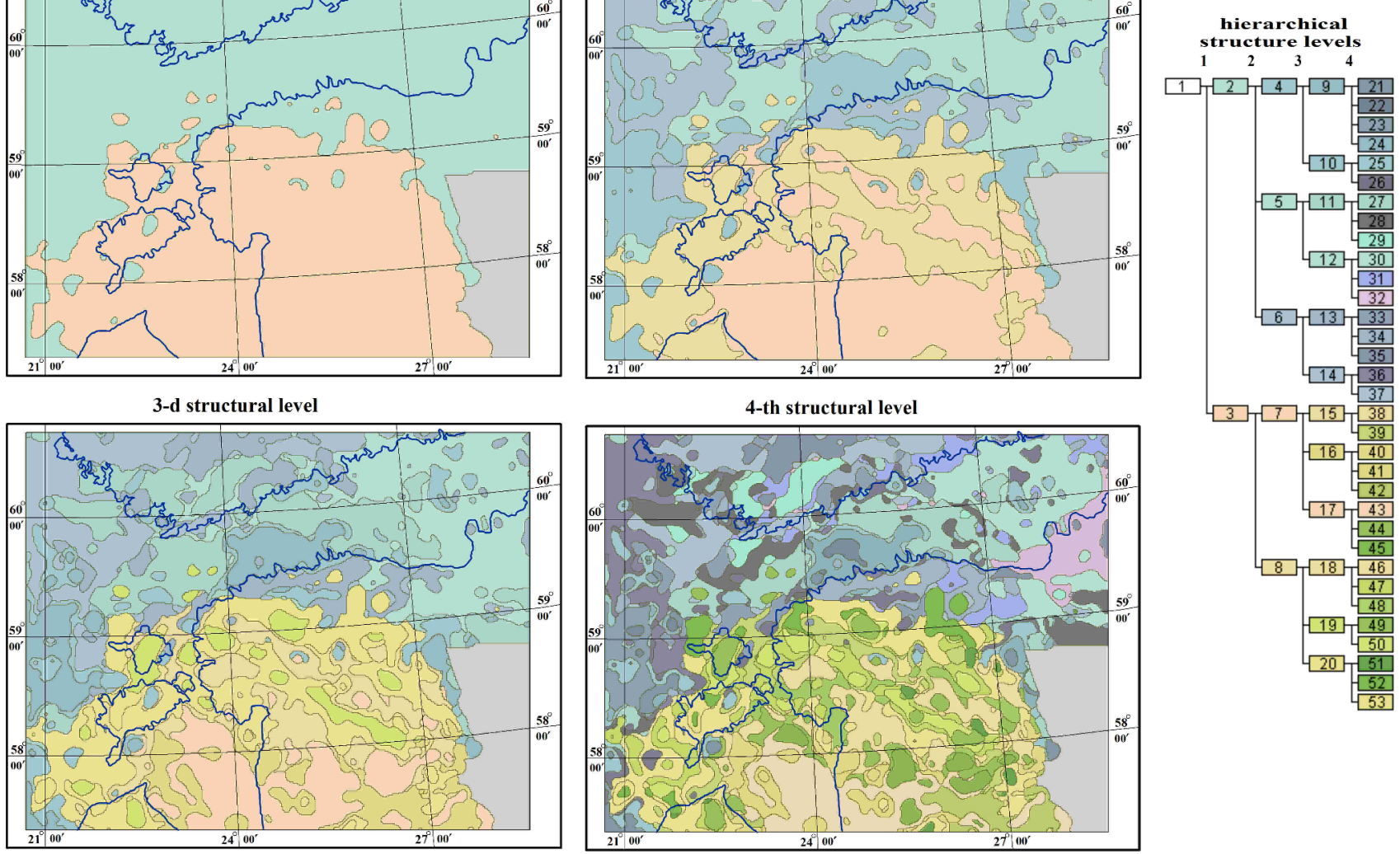

Figure 4. Development of the complex geophysical data structure.

resulting in development of a structural function;

3. determination of core level of division of feature sets into main clusters using a structural criterion, i.e. a jump in intercluster distances, at the same time, the main clusters are, as it were, prototypes of the main factors of initial features;

4. determination of characteristics of the main factors (correlations, intensity of image and structure, regression to initial features) and mapping of observation sites in the main feature space.

The main classes are determined in a similar way, using cluster analysis of objects and generalized Euclidean distance (Mahalanobis distance).

By means of division of the initial dataset into classes, it is made possible to construct a description of the tree-type structure of the data. The division characteristics include the following constitutional elements: names of classes and their volumes, main statistical characteristics, and a color code for compilation of a base map.

The description of classes of structural element is made in terms of the main factors, whereas the structure as a whole is described in terms of the observed features. The description in terms of the main factors makes it possible to assess their effect and place in the structure. As a means of structural characterization, it was set to use evaluation of feature variability in the initial class and, in addition, intraspecific variation. These evaluations are worked out in the course of analysis of deviations in both intra- and innergroup sums of squares (MSK and VSK). It becomes possible to carry out preliminary data processing accurately, manage the development of structure in a goal-oriented way, and get a quantitative evaluation of modeling results as a criterion to check that the model is consistent with observations. The structure's quantitative evaluation constitutes a relative proportion (in unit fractions, or per cent) of the initial data variation which is "made clear" by the worked out structure. If this indicator exceeds 0.5 , the result can be considered positive, even though, on the face of it, the pool of data looks rather heterogeneous.

A map of classes is developed by means of filling the spots on the map in concordance with preset index (color), which is set in the tree description during the construction of structure. Bearing resemblance to a geologic map, it constitutes the main result of the data research. Domain-specific interpretation of the map of classes is broken down into two stages: cartographic and geological [Berlyant, 1986] Burde, 1990. Firstly, elementary objects and relatively primitive cartographic images are isolated to make for linear disjunc- 
tive, ring-like and block images. To say more, there are features of classes in local areas and their contours that are taken as initial in this sort of data classification. Secondly, while giving a geological interpretation, the major significance falls onto the purpose of research, current knowledge of the territory geology, and generalized concepts of formation of crust segments in similar environments.

Speaking of the present study, visual expert analysis allowed conversion of the results into one map showing normalized standard deviations of features in classes. The conversion was basically made up of the following: construction of matrices of standard deviation as per class; normalization of matrix range in accordance with standard deviation of the feature in the initial pool of data; summarization of normalized standards in classes by 9 features. On this account, not only does the map make it possible to work out borders and shapes typical of complex subsurface geologic features, but also indicate the position of deformations, and, hence, moving block of the crust.

It is worth noting that the method of structural analysis was earlier applied in the study of seismotectonic position of the Kaliningrad earthquake of 2004 [Assinovskaya and Ovsov, 2008.

\section{Discussion and Results}

The research has resulted in the compilation of the following:

1. statistics table to evaluate the significance of the data analysis results (Table 1);

2. classification structure in form of a tree representing the data hierarchically and corresponding maps of complex data development (Figure 4), the map of the 4th structural layer constitutes a map of classes;

3. 12 maps of effective values anomaly of gravity $(G)$, magnetic $(T a)$ in conditional units, bathymetry and topography $(H)$ in $\mathrm{m}$, heat flow density $(Q)$ in $\mathrm{mW} / \mathrm{m}^{2}$, horizontal $(P L)$ and vertical $(Z)$ movements according to GPS data in mm/year (not included); 12 maps of standard deviations of features in classes (not included);

4. structural map constructed using indications of normalized standard deviations of generalized features Figure 5.

The Table 1 gives statistic evaluations as per hierarchical levels of all features ( 3 indications of gravity field $G_{-} F 1-3$, magnetic anomalies $T_{-} F 1-3$ and relief $H_{-} F 1-3,2$ GPS indications (horizontal and vertical) and 1 indication of heat flow density) in form of intragroup sum of squares. This value can be interpreted as contribution of the feature to the structure construction. The weighted average of the value with consideration of the factor loading, different for each distinct feature of the physical nature $(2-12 \%$ excluding the factor loading), amounts to $52.51 \%$, which proves the structure to be considerably consistent with the initial features.

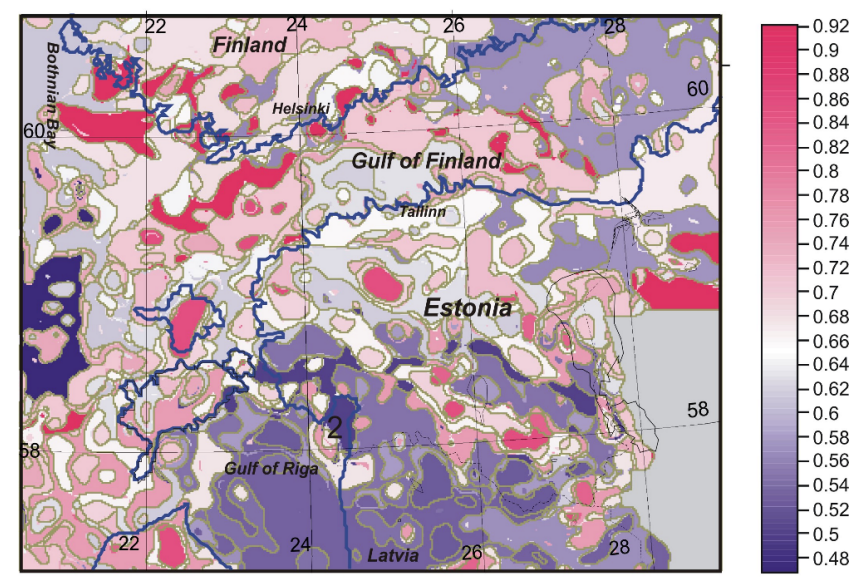

Figure 5. Normalized standard deviations of averaged value of features of $G, T a, H, P L, Z, Q$.

Figure 4 illustrates the evolution of hierarchical structure that is determined by the region's geologic evolution and, consequently, indicates the current tectonic pattern of the crust. The first level indicates the deepest structures, that is the way the Fennoscandian Shield, the Baltic Syneclise, and the Paldiski-Pskov deformation zone are revealed; the 3rd and 4th levels reveal sets of larger and smaller areas in form of domains and interblock borders, which are likely to indicate faults.

The most informative in terms of determination of areas with non-homogeneous crustal structure which normally connect with earthquake source zones is the map of normalized standard deviations of generalized features (further in text referred to as parameter) (Figure 5).

As can be seen from Figure 5, the parameter under study in terms of its value easily breaks down into the following:

1. high values (shades of pink);

2. intermediate values (indicated in white and grey color);

3. low values (shades of purple).

The zones are both linear and areal in form. Therefore, the region proves to be composed of relatively massive structures and non-homogeneous zones. In some cases, they take linear form and coincide with known faults. In particular, the parameter values are representatively high in the south branch of the Paldiski-Pskov deformation zone, whereas the North Latvian tectonic zone manifests itself as a sequence of the parameter's high and low values. Also, it turned out that the Bothnia-Finnish area is complex in its composition, internally containing a few linear areas with maximum values of the parameter and active deformation lineaments which are different in stretch and orthogonal to the Skonsero fault. Another zone to stand out is the one of the western border of Vyborg rapakivi granite intrusion as well as the non-homogeneity underlying the structure; Riga pluton is indicated as an isometric domain.

As a consequence, apparently, areas with abnormally high values of the parameter are likely to constitute a prototype of zones of possible earthquake sources. 
Table 1. Structural data variation based on complex analysis results

\begin{tabular}{|c|c|c|c|}
\hline Geophysical data & Factor weight in a feature, $\%$ & MSK, $\%$ & $\begin{array}{l}\text { MSK taking into in } \\
\text { account the weight, } \%\end{array}$ \\
\hline 1. Gravity field (G) & 100 & & 50.02 \\
\hline 1.1. $G \_F 1$ & 2.80 & 33.39 & 0.93 \\
\hline 1.2. $G \_F 2$ & 27.11 & 49.55 & 13.43 \\
\hline 1.3. $G \_F 3$ & 70.09 & 51.14 & 35.84 \\
\hline 2. Magnetic field (T) & 100 & & 35.27 \\
\hline 2.1. $T a_{-} F 1$ & 12.20 & 19.42 & 2.37 \\
\hline 2.2. $T a \_F 2$ & 56.73 & 40.00 & 22.70 \\
\hline 2.3. $T a_{-} F 3$ & 31.07 & 32.83 & 10.20 \\
\hline 3. Relief (H) & 100 & & 41.13 \\
\hline 3.1. $H_{-} F 1$ & 1.27 & 16.61 & 0.21 \\
\hline 3.2. $H_{-} F 2$ & 16.63 & 29.64 & 4.93 \\
\hline 3.3. $H_{-} F 3$ & 82.10 & 43.84 & 35.99 \\
\hline 4. GPS data & 100 & & 70.85 \\
\hline 4.1 GPS hor. & 50 & 75.01 & 37.50 \\
\hline 4.2. GPS vert. & 50 & 66.70 & 33.35 \\
\hline 5. Heat flow density & 100 & 65.28 & 65.28 \\
\hline Averaged on 5 features of different nature & & & 52.51 \\
\hline
\end{tabular}

Further in the course of analysis, there was applied a map of modern horizontal deformations of the Baltic region crust using GPS data (Figure 6), which had been earlier constructed in the framework of a different study [Gorshkov et al., 2013. The geodynamic lineaments have been constructed as a result of analysis of GPS stations horizontal movements, which allowed for construction of the modern horizontal deformation field of the Bothnia-Finnish region using the grid-stain method [Teza et al., 2008. The stress-

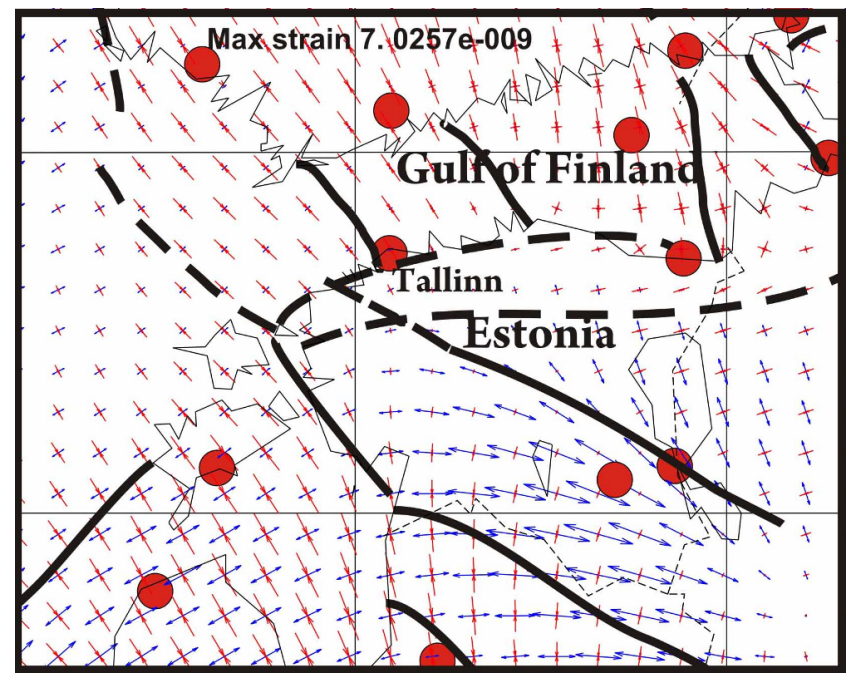

Figure 6. Horizontal deformation based on GPS observations from [Gorshkov et al.,2013]. Blue and red arrows show vectors of tension and compression, respectively. Red circles are station GPS. Black solid and dotted lines are active lineaments revealed reliably or unreliable respectively. deformation situation has proved to be instable in the region, varying from block to block. This regularity manifests itself more clearly in the areas where the GPS stations are located more densely. For example, the southern part of the Paldiski-Pskov tectonic zone is characterized by predominantly high-amplitude dilatation, whereas the North Latvian zone is indicated by intense strike-slip deformations. Riga pluton is an area of biaxial horizontal deformation. The Finnish graben is composed of several domains. The universal feature is the compression type of deformation; however, the orientation of vectors varies from $\mathrm{N}-\mathrm{W}$ trending to longitudinal. The North Estonian area is characterized by blank amplitudes of deformations, which can be explained by a wide pattern of observation sites. The borders of homogeneous deformation zones might probably constitute areas of present-day activity.

Figure 7 brings together planned locations of the parameter's maximum value zones, zones of tectonic faults that were inferred geologically from Figure 2, and geodynamic lineaments. To take these as seismogenic factors, one needs to make sure that the determined geodynamic deformations are not surface strains, but coincide to a greater or smaller extent with the deep seated tectonic faultings.

It is evident that the coincidence of all the three features should serve as the most active and prospective indicator of seismologically hazardous zones. Thus, for instance, the geologic fault of the southern branch of the Paldiski-Pskov deformation zone coincides in its stretch with the fairly wide linear zone of the parameter's increased values, as well as active geodynamic lineament. In contrast, the northern branch of the Paldiski-Pskov deformation is not clearly indicated both in the field of the parameter's increased values, and on the map of modern deformations.

In the meantime, the Skonsero fault with $\mathrm{N}-\mathrm{W}$ trending is likely to be active, since it is partly located within the 


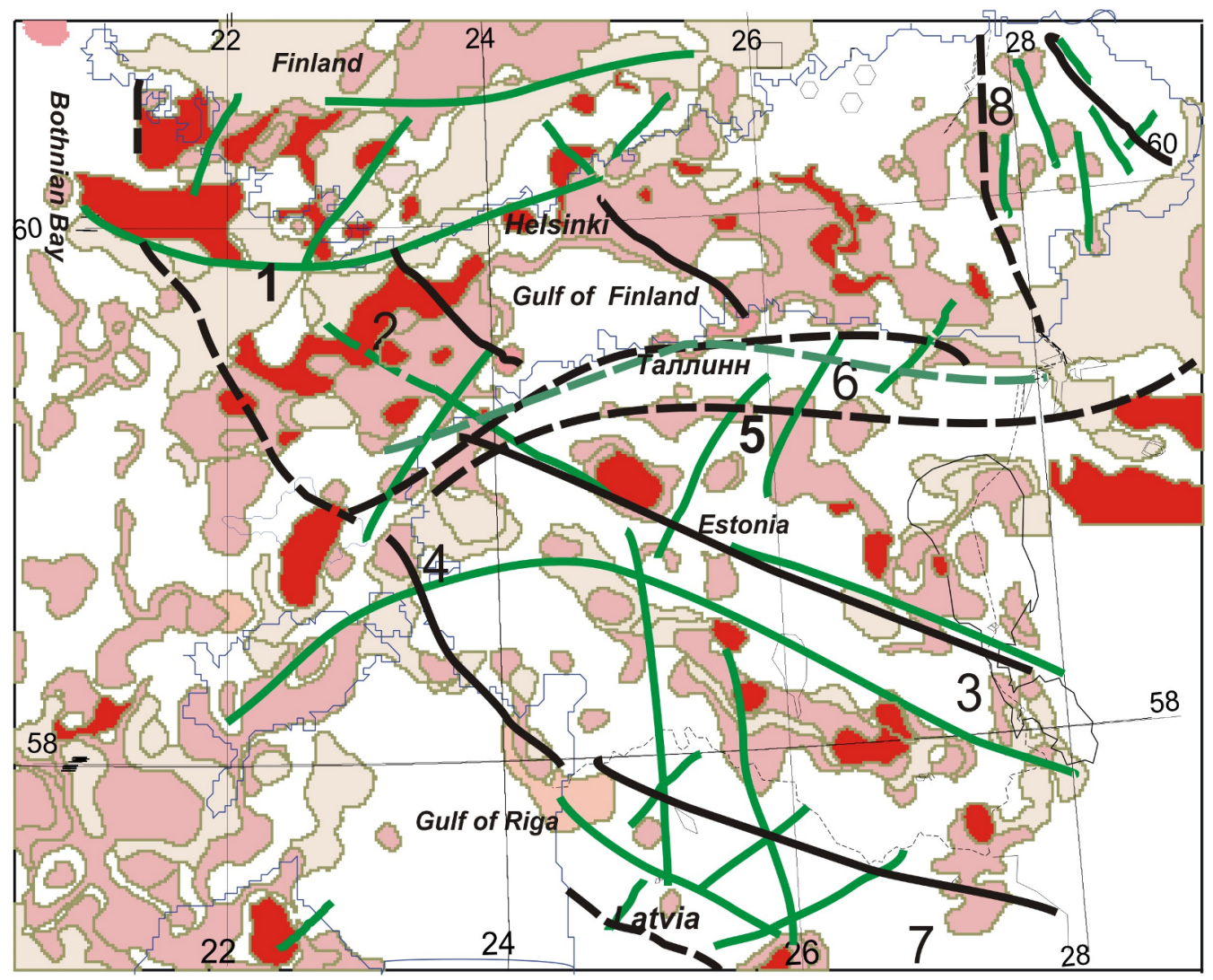

Figure 7. Maximum values $(>0.68)$ of parameter (see text) (shown in shades of red and pink). Geological faults are shown by green lines; active lineaments according to GPS are marked by black lines: solid and dashed lines show reliable or unreliable revealing respectively. Faults: 1, Southern Finland shear zone; 2, fault Skonsero; 3, Paldisky-Pskov deformation zone; 4, Middle Estonian fault, 5, Tapa fault zone; 6, Koporsky fault; 7, North Latvian fault zone.

field of the parameter's increased values, it is linked with active lineaments and sites in GPS data. Complete concordance of extensions by all features manifested itself for part of the Koporye fault. There is a partial concordance for the North Latvian zone of deformations, and the South Finnish shear zone. Riga rapakivi intrusion constitutes a zone of anomaly of areal shape. Vyborg intrusion is for the most part a massive structure, though its borders have been mapped in form of wide quasilinear areas of the parameter's increased values. Besides, within Vyborg intrusion there is a zone of non-homogeneous structure which partly coincides with faults determined geologically and by active geodynamic lineaments.

The area to the south-east of the Koporye tectonic deformation zone has not been investigated thoroughly enough in terms of its geodynamics, because there are no GPS stations there.

The presented data have resulted in a map of seismotectonic regionalization in form of areal and sublinear domains 1-9 (Figure 8). For mapping control, sources of representative earthquakes have been added to the map of domains; in general, distribution of sources proves the accuracy of the domains.
The detailed map analysis in comparison with the known geology allows for assumption that the form of the highlighted active zones and their size are induced by the block structure of the earth's crust, presence of systems of subparallel faults and tectonic joints, and also extensive intrusive formations of isometric shape, within which there are numerous smaller multiple-trending active faults. All mentioned destructive elements of the crust constitute an environment which contains earthquake source zones. It is worth stating that areas of contact or physical proximity of the determined zones constitute fault intersections.

From the seismogeologic point of view, zone 1 is areas of potential seismic activity of probably shear type at the depth of $7-14 \mathrm{~km}$; it relates tectonically to the Paldiski-Pskov zone of deformations described above. From among representative events, there have been 6 historical earthquakes and 3 instrumentally recorded ones with magnitudes of 1.9-4.2, the biggest occurred in 1670 around Pärnu with $M w=4.2$.

Interestingly, the northern branch of the Paldiski-Pskov zone of deformations is clearly associated with active lineament according to GPS data, whereas the southern branch is related to the anomaly of the parameter under study.

Zone 2 adjacent to zone 1 on the south contours the area 


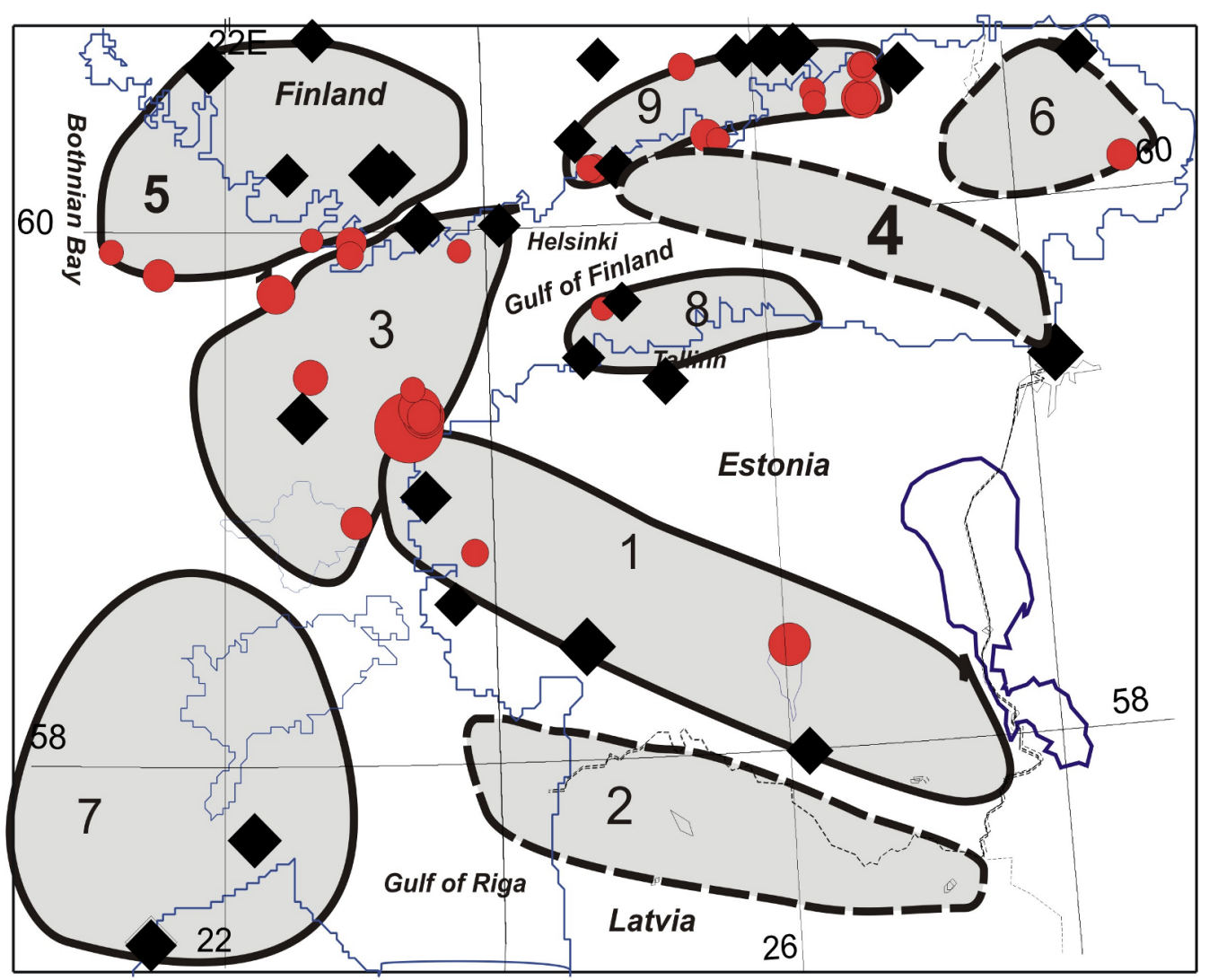

Figure 8. Seismotectonic zoning map. Areal zones are contoured by solid and dotted lines that means reliable or unreliable revealing respectively. Diamonds show representative historical earthquakes from 1670 to 1957, circles show representative events of instrumental period from 1958 to 2012 . The size of sign is proportional to the earthquake magnitude $M / 5$ in the range of $1.6-4.7$.

of intersection of the North Latvian fault with several orthogonal deformations. It is marked as prognostic because there have yet not been recorded any sources of earthquakes, but there are signs of activity. In terms of deep structure, zones 1 and 2 coincide with the area of jointing of the Shield with the Baltic Syneclise, which is indicated in the depth as zones of rapid changing in depth of the crust and its uppermost layer [Ankudinov et al., 1994. Tesauro et al., 2010.

It can be noted that at this scale level it is complicated to make a tectonic specification of zone 3. Supposedly, it is a tectonic joint formed by the Skonsero fault and the $\mathrm{N}-\mathrm{E}$ trending deformation. There were 20 representative events registered in the time span from 1757 to 2007 with $M w=1.6-4.7,6$ of which were historical. The sources depths vary from 7 to $17 \mathrm{~km}$. As was stated above, on 26th October, 1976, there occurred one of the biggest events in the Baltic region on the border with zone 1 . Tectonically, the source of the Osmussaar earthquake with $M w=4.6$ and its 4 aftershocks are associated with the area of intersection of several faults, such as the Skonsero, Kaporsky, PaldiskiPskov zones of deformation and some others.

Zone 4 is viewed as prognostic. It stretches as a wide strap along the south-western border of Vyborg rapakivi granite intrusion. The zone is highlighted in connection with all specified prognostic features in the framework of the study, such as presence of the parameter's anomaly and geodynamic lineament. Moreover, in the south-east, the zone borders tightly with the source zone of the Narva historical earthquake of 1881 which has been studied seismotectonically [Nikonov, 2010].

Zone 5 of isometric shape is formed by a group of active multiply-oriented deformations, the main one of which constitutes the South Finnish shear zone. Within its borders, 9 (6 historical) representative earthquakes in 1925-2012 with $M w=1.7-4.2$ at the depths of 1-14 km occurred there. The biggest event was earthquake with intensity $6(M w=4.2)$ that occurred on 12th December, 1934. Geological methods allowed for detection of an old shear zone around the Aland Islands.

Zones 6 and 7 are associated with the areas of nonhomogeneity on the borders and inside rapakivi granite intrusions. According to the available seismic data, they are capable of inducing shallow $(H=1-2 \mathrm{~km})$ and weak earthquakes; there occurred at least 3 historical events (1785, 1857, 1870) and 1 (2007) instrumental one. Domain 6 contours a zone of crustal non-homogeneity inside Vyborg rapakivi intrusion sunken hypsometrically and tectonically. Domain 7 saw an earthquake in 1857, which was felt with intensity 7 in the epicenter, though the depth of the source was $1 \mathrm{~km}$. 
Shallow focus zone 8 (source depth under $6 \mathrm{~km}$ ) is associated with the geodynamically activated segment of the Kaporsky fault. Within the zone, there occurred 4 historical earthquakes and 1 event registered instrumentally in the time span of 1869-2006; their magnitude range from $M=1.6$ to $M=3.0$.

Zone 9 is the most active of all. There occurred 38 representative evens, 28 of which were historical with magnitudes of $1.7-3.6$ at the depths range of $1-11 \mathrm{~km}$. It is characteristic of the zone to have source clusters, it is known about sequences of 1751,1951 , and 1952. The zone is located on the edge of the region under study and apparently extends further to the north. It can be assumed that it is formed by small tectonic deformations of $\mathrm{N}-\mathrm{W}$ trending, although some authors indicate a subjacent deformation stretching along the north coast of the Gulf of Finland. There are anomalies of all the factors analyzed in the article.

In order to compile a full-scale map of possible sources of earthquakes, it is critical to estimate the recurrence of events and a value of the highest possible magnitude of a forecasted earthquake for each of the zones; this will serve as a purpose of the next stage of the research.

\section{Conclusions}

1. For the first time in seismology, there has been applied a combination of the structural analysis of geophysical data and method of geodynamics to determine zones of possible sources of earthquakes.

2. As a result, in the region, instead of just three domains determined by expert analysis on the SHARE map Figure 1, there has been generated a fairly complex configuration of potentially seismogenic areal structures. Almost all active zones have proved to extend to the north-west, transverse to the Finnish graben. By comparison with the previous study [Assinovskaya and Ovsov, 2013, the map of seismotectonic regionalization has been significantly detalized.

3. The structural analysis technology has been proved to be applicable once again, which has expanded its use well beyond the earlier few applications restricted by geological mapping and works on assessment of seismic hazards.

4. The described set of methods can find their application in determination of active zones in other regions of low seismicity, especially those tectonically underexplored.

\section{References}

Alexandrov, V. V. (2000), Developing Systems in Science, Technology, Society and Culture: Part I. Systems Theory and Systems Modeling, 244.
Ananjin, I. V., N. K. Bulin, E. R. Klaaman (1980), Osmussaar (Estonian) earthquake October 25th 1976, Earthquakes in USSR in 1976, 91-97.

Ankudinov, S., A. Sadov, H. Brio (1994), Crustal structure of Baltic countries on the basis of deep seismic sounding, Proceedings of the Estonian academy of Sciences, 43, 3, 129-136.

Aronov, A. G, T. I. Aronova (2009), Seismotectonic Criteria for Long-Term Forecast of the Kaliningrad Earthquakes, Kaliningrad Earthquake September 21, 2004, 136-151.

Assinovskaya, B. A., M. K. Ovsov (2008), Seismotectonic position Kaliningrad earthquake September 21, Physics of the Earth, 9, $32-43$.

Assinovskaya, B. A., M. K. Ovsov (2013), Seismotectonic regionalization of the Eastern Baltic region based on computer analysis method, Georisk, 3, 48-56.

Assinovskaya, B. A., V. L. Gorshkov, N. V. Scherbakova, N. M. Panas (2013), Active faults established according to geodynamic observations in the Baltic Sea, Engineering surveys, 2, $50-55$.

Assinovskaya, B., J. Shchukin, V. Gorshkov, N. Shcherbakova (2011), On GPS and earthquake dynamics for the parts of the Eastern Baltic region, Baltica, 24, 2, 61-70.

Assinovskaya, B. A., N. N. Verzilin (2007), On the Seismic Hazard in the Baltic Sea, Changing Geological Environment: SpaceTime Interaction of Endogenous and Exogenous Processes, Proceedings of the International Conference. Volume 1: Kazan; 13-16 November 2007, 210-214.

Balling, N. (1995), Heat flow and thermal structure of the lithosphere across the Baltic Shield and Northern Tornquist Zone, Tectonophysics, 1-3, 13-50, doi 10.1016/0040-1951(94)00215-U

Berlyant, A. M. (1986), Image of Space: The Map and the Information, 240.

Berzin, L. Z., H. S. Brio, L. P. Karpitskaya, Y. A. R. Klavin, N. K. Ozolin (1979), Role of Heredity in the Formation of Recent Structural Plan of the Sedimentary Cover in Latvia. Problems of Heredity Tectonic Structures in the Baltic States and Belarus, Tallinn, 20-26.

Bommer, J. (2010), Harmonizing seismic hazard assessment in Europe, SECED Newsletter, 22, 2, 3-10.

Burde, A. I. (1990), Cartographic Method of Research at Regional Geological Studies, 251.

Garetzki, R. G., S. A. Nesmjanov (Eds.) (2009), Seismotectonics of Plates of Ancient Platforms in the Quaternary Glaciation, 228 .

Gorbachev, R., S. Bogdanova (1993), Frontiers in the Baltic Shield, Precambrian Research, 64, 3-21.

Gorgienko, V. V., O. V. Zavgorodnja, U. I. Moiseenko (1987), Heat flow map of the European part of the USSR, Scale $1: 5,000,000$, Explanatory note, VSEGEI, Leningrad, 35.

Gorshkov, N. V., N. M. Scherbakova, B. A. Assinovskaya (2013), GNNS observation results in Eastern Baltic region and their interpretation, Modern methods of elaboration and interpretation of seismological data, Materials of the 8-th International seismological school, Obninsk, GS RAS, 145-148.

Grad, M., T. Tiira and ESC Working Group (2009), The Moho depth map of the European Plate, Geophys. J. Int., 176, 279292, doi 10.1111/j.1365-246X.2008.03919.x

Grachev, A. F., V. A. Nikolaev (2002), Problems of the Pannonian Basin geodynamics, Russian Journal of Earth Sciences, 4, 5, 331-361, doi 10.2205/2002ES000105

Janik, T. (2010), Upper Lithospheric Structure in the Central Fennoscandian Shield: constraints from $\mathrm{P}$ - and S-wave velocity models and VP/VS ratio distribution of the BALTIC wide-angle seismic profile, Acta Geophysica, 58, 4, 543-586, doi $10.2478 / \mathrm{s} 11600-010-0002-0$

Jiménez, M. J., D. Giardini, G. Grünthal and the SESAME Working Group (2001), Unified seismic hazard modeling throughout the Mediterranean region, Bull. Geof. Teor. Appl., 42, 3-18.

Joeleht, A., I. T. Kukkonen (1996), Heat flow density in Estonia - assessment of paleoclimatic and hydrogeological effects, Geophysica, 32, 3, 291-317.

Kirs, J., V. Puura, A. Soesoo, V. Klein, M. Konsa, H. Koppelmaa, M. Niin, K. Urtson (2009), The crystalline basement of 
Estonia: rock complexes of the Palaeoproterozoic Orosirian and Statherian and Mesoproterozoic Calymmian periods, and regional correlations, Estonian Journal of Earth Sciences, 58, 4, 219-228, doi 10.3176/earth.2009.4.01

Koistinen, T., M. B. Stephens, V. Bogatchev, O. Notdgulen, M. Wennerstrom, J. Korhonen (2001), Geological Map of the Fennoscandian Shield, scale 1:2,000,000, Geological Surveys of Finland, Norway and Sweden and the North-West Department of Natural Resources of Russia.

Korhonen, J. V., et al. (2002a), Bouger Anomaly Map of the Fennoscandian Shield. Scale 1:2,000,000, The Geological Surveys of Finland, Norway and Ministry of Natural Resources of the Russian Federation.

Korhonen, J. V., S. Aaro, T. All, H. Nevanlinna, J. R. Skilbrei, H. Saavuori, R.Vaher, L. Zhdanova, T. Koistenen (2002b), Magnetic Anomaly Map of the Fennoscandian Shield. Scale 1:2,000,000, The Geological Surveys of Finland, Norway and Ministry of Natural Resources of the Russian Federation.

Korsman, K., T. Koistinen, J. Kohonen, M. Wennerström, E. Ekdahl, M. Honkamo, H. Idman, Y. Pekkala (Eds.) (1997), Bedrock Map of Finland, 1:1,000,000, Geological Survey of Finland.

Kozlovskaya, E., G. Kosarev, I. Aleshin, I. Riznichenko, O. Sanina (2008), Structure and composition of the crust and upper mantle of the Archean-Proterozoic boundary in the Fennoscandian shield obtained by joint inversion of receiver function and surface wave phase velocity of recording of the SVEKALAPKO array, Geophys. J. Int., 175, 135-152, doi $10.1111 / \mathrm{j} .1365-$ 246X.2008.03876.x

Lidberg, M., J. M. Johansson, H.-G. Scherneck, G. A. Milned (2010), Recent results based on continuous GPS observations of the GIA process in Fennoscandia from BIFROST, Journal of Geodynamics, 50, 8-18, doi 10.1016/j.jog.2009.11.010

Majorowicz, J., S. Wybraniec (2010), New terrestrial heat flow map of Europe after regional paleoclimatic correction application, International Journal of Earth Science, published online, doi $10.1007 / \mathrm{s} 00531-010-0526-1$

Nikonov, A. A. (2002), Osmussaar earthquake 25.10.1976: Macroseismics, seismotectonics, focal mechanism, Physics of the Earth, 8, 74-88.

Nikonov, A. A. (2010), Narva earthquake 28.01.1881 in the eastern part of the Gulf of Finland, Questions of Engineering Seismology, 37, 4, 35-46.

Ovsov, M. K. (1990), Combined method of cluster and factor analysis of variables in applied geochemistry, Izvestiya Vuzov. Geology and Exploration, 1, 60-66.

Ovsov, M. K. (1997), Logical foundations of classification and typology, Abstracts of the First Russian Congress of Philosophy "Man philosophy, humanism", 230.
Ovsov, M. K. (2000a), Intellectual operation of structural analysis. Article I, Izvestiya Vuzov. Geology and Exploration, 1, 105-114.

Ovsov, M. K. (2000b), Intellectual operation of classification. Article II, Izvestiya Vuzov. Geology and Exploration, 4, 107-114.

Ovsov, M. K. (2001), Classification as product constructions. Article III, Izvestiya Vuzov. Geology and Exploration, 2, 93-101.

Ovsov, M. K. (2005), Measures of similarity and categories of hierarchies. Proceeding of VII International Conference "New Ideas in Earth Sciences", Moscow, MGGRU, 230.

Ostrovsky, A. A. (1995), Ancient rifting zone under the Baltic Sea, DAN, 342, 5, 680-685.

Rozova, S. S. (1986), The Classification Problem in Modern Science, 225.

Sharov, N. V., A. A. Malovichko, Ju. K. Schukin (2007), Earthquakes and Microseismicity of East European Platform - Recent Geodynamic Approach. Book 1 - Earthquakes, 381.

Shilova, T. M., V. R. Verbitsky (2009), Regional potential fields, Kaliningrad Earthquake September 21, 2004, A. V. Nikolaev (ed.), St.-Petersburg, VSEGEI, 41-45.

Slunga, R. (1979), Source mechanism of a Baltic earthquake inferred from surface-wave recordings, Bull. Seism. Soc. Am., 69, 6, 1931-1969.

Tesauro, M., M. K. Kaban, S. A. P. L. Cloetingh (2010), 3D crustal Model of western and Central Europe as a basis for Modelling Mantle Structure, New frontiers in integrated Solid Earth sciences. International Year of Planet Earth, S. Cloetingh, J. Negendank (eds.), 39-69.

Teza, G., A. Pesci, A. Galgaro (2008), Grid_strain and grid_strain3: Software packages for strain field computation in 2D and 3D environments, Computers \& Geosciences, 34, 9, 1142-1153.

Ulomov, V. I., M. I. Bogdanov (2013), A new set of maps of general seismic zoning of the Russian Federation (OSR 2012), Engineering Surveys, 8, 30-39.

Uski, M., T. Tiira, A. Korja, S. Elo (2006), The 2003 earthquake swarm in Anjalankoski, south-eastern Finland, Tectonophysics, 422, 1-4, 55-69, doi 10.1016/j.tecto.2006.05.014

Vaisanen, M., P. Skytta (2007), Late Svecofennian Shear Zones in Southwestern Finland, GFF, 129, 55-64, doi 10.1080/11035890 701291055

Yliniemi, J., et al. (2001), EUROBRIDGE'95 deep seismic profiling within the East European Craton, Tectonophysics, 339, $1-2,153-175$.

B. A. Assinovskaya and M. K. Ovsov, Geophysical Survey RAS, Saint-Petersburg, Pulkovskoye shosse, 65, k. 12, 196140 , Russia. 